\title{
Macroeconometric modelling and Pakistan's economy
}

\section{A vector autoregression approach}

\author{
Salim U. Chishti*
}

AERC. University of Karachi, Pakistan

\section{Aynul Hasan}

The Johns Hopkins University, Baltimore MD, USA

Acadia University, Wolfville, Nava Scotia, Canada

\section{Syed F. Mahmud}

Bilkent University, Ankara, Turkey

Received February 1990, final version received June 1991

Recent applications of the Vector Alitoregression (VAR) technique pioneered by Sims, Litterman and Doan has become popular in macroeconomic modelling, particularly when knowledge about 'true' structural relations is absent. This study represents the first at tempt to apply such a technique to Pakistani data for ten key macroeconomic variables. Unlike some of the earlier studies on Pakistan's economy our empirical results are intuitive and consistent with the predictions of the standard new neoclassical model. More importantly, based on these results, perhaps, one may also shed light on some of the dominant recurring macroeconomic issues of Pakistan's economy.

\section{Introduction}

Government stabilization policies play an important role in influencing the

Correspondence to: Dr. M. Aynul Hasan, Department of Economics, Acadia University. Wolfville, Nova Scotia BOP 1X0, Canada.

* We wish to thank M. Ali Khan, Mohsin Klyan, Jere Behrman, Steve Blough, Etezm? Ahmed and the two anonymous referees for their useful comments which has significantly improved this version of the paper. M.A. Hasan wishes to thank T. Doan, C. Sims, I. Raynausd and M. Wheeler for earlier helpful discussions on the methodology of VAR technique. He also wishes to thank the Social Sciences and Research Council of Canada for funding his visit to the Apphied Ecunomics Research Centre (AERC). University of Karachi, where the research for this paper was initiated. An earlier version of the paper was presented at the Sixth Annual Meering of the Pakistan Society of Development Economists. 
macroeconomic performances of developing economies including Pakistan. However, there is little known, with authenticity, about the channels through which changes in these policies percolate throughout the system. A few studies have attempted to address these issues in Pakistan using both large and medium size structural models [Naqvi et al. (1983, 1986), Saqib and Yasmin (1987), Masood and Ahmed (1980) and Hasan (1987, 1990)]. But some of these studies have reached contradictory and, at times, even counterintuitive conclusions depending on the pre-specifications of the structural relations used.

In the absence of any lnowledge about 'true' relations, the recent applications of the Vecter Autoregression (VAR) technique pioneered by Sims (1980, 1982 and 1986) and popularized by Doan et al. (1984), we believe, is a possible alternative as this approach seems to be more flexible than macro modeiling. Às opposed to the conventional structural macroeconomic models, the VAR technique does not require any explicit iconoinic theory to estimate a model. It also allows one to capture empirical regularities in the data using fewer key macro variables and thereby providing insight into channels through which the different policy variables operate.

Our study represents the first attempt to apply such an approach in the case of Pakistan. In this paper, we develop and estimate an annaul macroeconometric model for the economy of Pakistan over the period 1960 to 1988 using the innovative VAR technique proposed by Litterman (1979, $1984)$ and Sims (1980, 1982 and 1986). The primary focus of this study is to analyze empirically the strength of short-run and long-run impacts of anticipated and unanticipated monetary and fiscal policies and external resourses and remittances shocks (or innovations) on Pakistan's macroeconomy.

The VAR macroeconometric model estimated in this paper includes ten key macroeconomic variables [i.e., real GDP ( $R G D P)$, consumer price index $(P)$, terms of trade between agriculture and manufacturing sectors (TTAM), unemployment rate $(U E M)$. real investment $(R I N V)$, real value of remittances $(R E M)$, real exports $(R E X P)$, real external resources $(R E X R)$, money stock $(M)$ and real government expenditure $(R G E X)]$. The anticipated policy analysis is conducted using an $F$-test on the estimated coefficients while the unanticipated policy shocks are analyzed with impulse response functions and variance decompositions (VDCs) obtained from the moving-average representations of the VAR model.

The results of our study include a moderate impact of fiscal policy shocks on monetary expansion, at least in the short run, and a sirong delayed effect of monetary expansion on the seral price level.

The organization of the paper is as follows. In section 2 we discuss the VAR estimation procedure, the impulse response functions and the variance 
decompositions. Section 3 presents the data, model specification and the icsults. Concluding remarks appear in section 4.

\section{YAR methodology}

In order to analyze the impact of policy variables on macroeconomic targets, a standard complete structural macro model is probably desirable. However, such a model can be extremely tightly structured with numerous arbitrary 'exclusion' or 'zero restrictions' imposed on the coefficients of the variables in the model. These very strong restrictions on the model may inhibit researchers from revising the macro model even when the data or historical evidence points to such a need. Consequently, many model builders are likely to find these exclusion restrictions in the structural models too extreme and inflexible. Faced with these problems, many researchers have recently adopted an alternative method pioneered by Doan, Litterman and Sims (1984) which uses the modern time series technique known as the Vector Autoregression (VAR) method.

The Vector Autoregressive model provides a simple means of explaining or predicting the values of a set of economic variables at any given poini in time. VAR is a straightforward, powerful statistical forecasting technique which can be applied to any set of historical data. Like the structural model, the VAR system also generates systems of equations that can project the future paths of economic variables extrapolating from their past historical values. However, the main difference between the VAR system and the structural models is that, unlike the structural model, the VAR system is based entirely on empirical regularities embedded in the data. While the structural model is tied closely to the economic theory and has to follow the assumptions and the a priori restrictions imposed therein, the VAR model does not have to resort to the theory per se as, in fact, the data determines the final system.

Another important issue that deserves some discussion in this context is the problem of robustness of the results of the estimated VAR models. Some researchers [e.g., King (1983), Runkle (1987) and Spencer (1989)] have argued that the empirical results from VAR models are nonrobust and that by changing a model slightly can produce significantly different results. Sims (1987 and 1989), on the other hand, had refuted these claims. In a recent paper, however, Todd (1990) objectively examined both sides of the debate and in this context he pointed out that:

In some respect, this continuing debate between Sims and his critics is anachronistic. The debate has more or less outlived the object of Sim's investigation... In other respect, however, this debate remains timely and important. The findings of Sims and his critics have been used to 
support broad claims that continue to color general opinions of not only VAR analyses but also time series analyses in general. (p. 20).

Reconciling both sides of the robustness debate, Todd (1990) further argued:

At the more general level, I again find some truth on each side. I agree with the critics that many results from VAR models, at least those constructed with generic macroeconomic variables... may in fact not be robust. However, I also agree with Sims that nonrobustness is not a general property of VAR results and that even simple VARs can sometimes provide usefu! evidence on economic issues. In short, it is not generally true that a!! VAR results are robust or that none are. What does seem true... is that researchers using VARs should check their results for robustness. (p. 20).

In this paper, we have adopted Todd's suggestion and in the next section we demonstrate that our estimated results using the VAR approach, to a reasonable extent, are robust.

\subsection{Estimation procedure}

An $n$ variable VAR system can be written as

$$
A\left(\ell, Y_{t}=A+U_{t}\right.
$$

and

$$
A(\ell)=I-A_{1} \ell-A_{2} \ell^{2}-\cdots A_{m} \ell^{m},
$$

where $Y_{t}$ is an $n \times 1$ vector of macroeconomic variables, $A$ is an $n \times 1$ vector of constants, and $U_{t}$ is an $n \times 1$ vector of random variables, each of which is serially uncorrelated with constant variance and zero mean. ${ }^{1}$ Eq. (2) is an $n \times n$ matrix of normalized polynominai in the lag operator $\ell\left(\ell^{k} Y_{t}=Y_{t-1}\right)$ with the first entry of each polynomial on $A$ 's being unity.

Since the error terms $\left(U_{t}\right)$ in the above model are serially uncorrelated, a simple ordinary least squares (OLS) technique would be appropriate to estimate the model. However, before estimating the parameters of the model $A(\ell)$ meaningfully, one must limit the length of the lag in the polynomials. If $\ell$ is the lag length, the number of coefficients to be estimated is $n(n t+c)$, where $c$ is the number of constants.

In the VAR model presented above, the current innovations $\left(U_{t}\right)$ are

\footnotetext{
'The vector of residuals $\left(U_{1}\right)$ may not necessarily be contemporaneously uncorrelated. However, using the Choleski decomposition [as suggested by Doan (1989)] one may empirically test for such collinearity of the residuals. We have adopted this procedure to test for orthogonality as is explained in footnote 6.
} 
unanticipated but become part of the information set in the next period. This implies that the anticipated impact of a variable is captured in the coefficients of lagged polynomials while the residuals capture unforeseen contemporaneous events. Hence, even though a direct interpretation of the estimated individual coefficients from the VAR system is very difficult [e.g., see Sims $(1980$, p. 20)], a joint $F$-test on these lagged polynomials is, nevertheless, usefu! in providing information regarding the impact of the anticipaied portion of the right-hand side variables.

In order to analyze the impact of unanticipated policy shocks on the macro variables in a more convenient and comprehensive way, Sims (1980) proposed the use of impulse response functions (IRFs) and variance decompositions (VDCs) that are obtained from a moving average representation of the VAR model [eqs. (1) and (2)] as shown below:

$$
Y_{t}=\text { Constant }+H_{i}(\ell) U
$$

and

$$
H(\ell)=I+H_{1} \ell+H_{2} \ell+\ldots,
$$

where $H$ is the coefficient matrix of the moving average representation which can be obtained by successive substitution in eqs. (1) and (2). The elements of the $H$ matrix trace the response over time of a variable $i$ due to a unit shock given to variable $j .^{2}$ In fact, these impulse response functions will enable us to analyze the dynamic behaviour of the target variables (RGDP, P, TTAM, $U E M$ and $R I N V)$ due to unanticipated shocks in the policy variables ( $R G E X$ or $M$ ).

Having derived the variance-covariance from the moving-average representation, one can then construct the VDCs. VDCs show the portion of variance in the prediction for each variable in the system that is attributable to its own innovations and to shocks to other variables in the system. In our case, we are most concerned by the portion of the variance in the traget variable(s) that can be explained by shocks to policy variables ( $M$ or $R G E X$ ) and some other relevant exogenous variables of interest (i.e., $R E Y K$ and $R E M)$.

\section{Data, estimation and the VAR results}

\subsection{Data and the model specification}

Our model includes ten key macroeconomic variables (as mentioned in

\footnotetext{
${ }^{2}$ Note that the impulse response functions (IRFs) are not unat free. Therefore, in ofder to compare the IRFs of different variables the IRFs are standardized by dividing each IRE by its standard deviation. [See Doan (1989) for detailed procedure.]
} 
section 1) that are common to most small macroeconomic models. They are obtained from the Data Bank of the AERC Macroeconometric Model. ${ }^{3}$ We believe that these key macroeconomic variables should cover the small open economy and other broader aspects of the economy of Pakistan. All the variables, except $U E M$ and TTAM, are in natural logarithmic form. ${ }^{4}$

\subsection{Estimation}

Choosing lag length. Following Doan (1989) and Sims (1980), an appropriate likelihood-ratio test is used to determine the lag length for the VAR model. ${ }^{5}$ Using the sample period $1960-1988$, and based or the significance of the Chi-square $\left(\chi^{2}\right)$ value, a lag lengtil of two was adopted in this study.

\subsection{Results}

$F$-test results. As mentioned earlier, the significance of $F$-tests on a group of coefficents estimated using the VAR technique provides a convenient summary for analyzing the impact of the anticipated policies on the target variables. The significance levels of the $F$-tests, based on the hypothesis that all lags of a given variable for a particular equation are zero, are reported in table 1 . A value of 0.274 , for instance, in row 2 and column 11 indicates that the hypothesis of two lagged coefficients of $R G D P$ in the regression equation of $M$ being both equal to zero [i.e., $\mathrm{H}_{0}: \beta_{1}=\beta_{2}=0$ (based on $F$ - distribution)]

\footnotetext{
${ }^{3}$ Indeed. a much larger model with more variables would be desirable and would probably capture the finer details of the economy. However, in explaining such a model we may run into serious degrees of freedom problems. For instance, with 10 variables $(n)$ and 2 lags $(\mathscr{\ell})$, one would need to estimate $20(n \times \ell)$ parameters for each equation. By including just one additional variable into the model the number of parameters to be estimated increases to 22 . In addition, if the number of lags is izcreased by 1 , then with the same model the estimated parameters jump to 30 .

${ }^{4}$ In transforming a variable, a natural question arises as to whether one should do an appropriate differencing to identify the stationarity structure of the process. In this context, Doan (1989) noted that differencing a variable is 'important' for at least two reasons in the case of Box-Jenkins ARIM A Modeling: (a) the identification of the stationary structure of the series becomes very difficult using the sample autocorrelation function of the integrated process; (b) when faced with integrated series most of the computer 'algorithms' fail in fitting ARIMA models. Neither of these concerns, however, is relevant to the VAR models. As a matter of fact, Fuller [(1976, Theorem 8.5.1)] has shown that differencing the data may not produce any gain so far as the 'asymptotic efficiency' of the VAR is concerned 'even if it is appropriate'. In fact, he even argued that differencing a variable 'throws information away' while producing no जigrificant gain. Thus, following Doan (1989) and Fuller (1976), we have avoided differencing our variables:

${ }^{5}$ It should be noted that the traditional likelihood-ratio test used to test the lag lengths suffers from the criticism of not adequately taking into account the sample size. Sims (1980), however, has proposed an alterative formula which appropriately coriects for its sample size. The recent version of the RATS (3.02) programme, which provides such a subroutine, has been used in this paper to determine the lag length. [For the exact formula and the procedure, see Doan (i989, pp. 6-8)].
} 


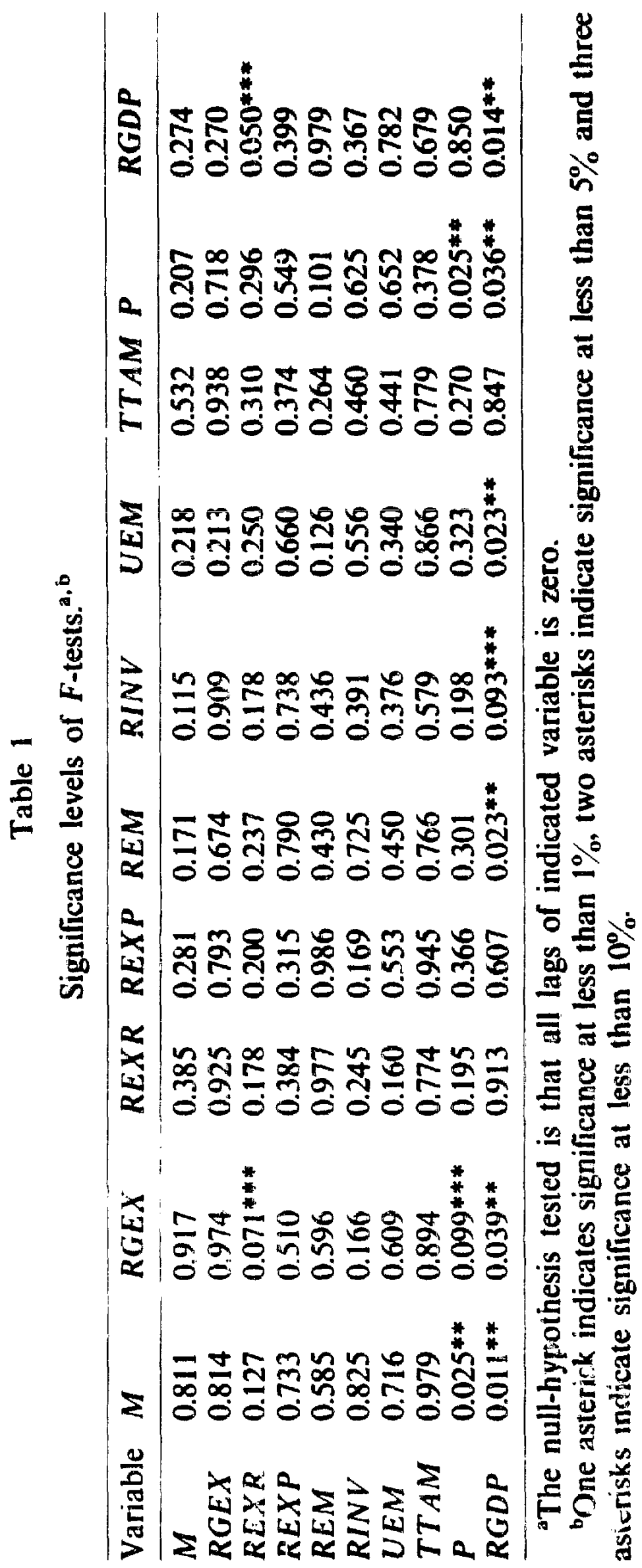


is accepted only 27.4 times out of 100 (or rejected as many as 72.6 times out of 100 ).

The results in table 1 clearly reveal that the monetary $(M)$ and fiscal $(R G E X)$ policy variables and two other variables of interest i.e., external resources $(R E X R)$ and remittances $(R E M)$ are purely exogenous and they are, in general, not influenced by other variables. This can be seen by looking at the significance level of the relevar' $n$ licy variables across a given row in table 1. For instance, in the case of $R G E X$, all values of the significance levels of the $F$-test (across the row) are, at least. greater than 0.270 .

Table 1 also reveals that the target variable (RGDP) is strongly influencus by the anticipated fiscal $(R G E X)$ and monetary $(M)$ policies and remittances $(R E M)$ [significant $F$-tesi values in the last row $(0.01,0.029$ and 0.022 , respectively)], while the impact of the external resource $(R E X R)$ variable is highly insignificant (0.913).

Impulse responses. The results presented, so far, only enable us to analyze the impact of anticipated policies. Furthermore, it has been aigut 3 that the distributec lag coefficients estimated using VAR do not provide a clear understanding of the implied dynamic behaviour of the model. Sims (1980), therefore, suggested the use of impulse response coefficients which will enable us to analyze the dynamic behaviour of a variable due to random shocks given to other variables. ${ }^{6}$ In fact, the graphs of the impulse response coefficients provide a better device to analyze the shocks and, therefore, the following aiscussion is devoted to the analysis of these graphs.

In order to capture the dynamic effects, we considered responses over five years to a one standard deviation shock in each variable. Since the primary focus of this study is to analyze the impacts of fiscal (RGEX) and monetary $(M)$ policies and, to a lesser extent, the external resources (REXR) and remittances $(R E M)$, we have only presented the graphs of impulse responses to shocks of these policy variables and they are shown in figs. 1, 2, 3 and 4, resnectively. The following is a summary of the results of impulse responses:

(a) Inspection of fig. 1 reveals that a one stanciard deviation shock given to $M$ produces a strong positive delayed impact on $R G D P$ and $R I N V$, and it takes about two years before reaching a peak. While the economy is in the expansionary phase, the impact of an initial increase in the nominal balances

\footnotetext{
"It should be noted that before computing the impulse response functions one should first orthogonalize the innovations. In this paper, we used the Choleski decomposition method, as suggested by Doan (1989). io orthogonalize the variance-covariance matrix of the innovations. It is true that the Choleski decomposition is not unique with respect to the ordering of the variables except in cases where the VAR covariance matrix is diagonal. Following Sims (1980), we have triangularized the system. Based on macroeconomic theory, we tried several orderings of the variables with policy variables appearing first and the target variables at the futiom. Since varying the order does not substantially alter the results, we have reported the results of only one ordering in this naper. [For a detailed explanation of this technique, see Doan (1989)].
} 

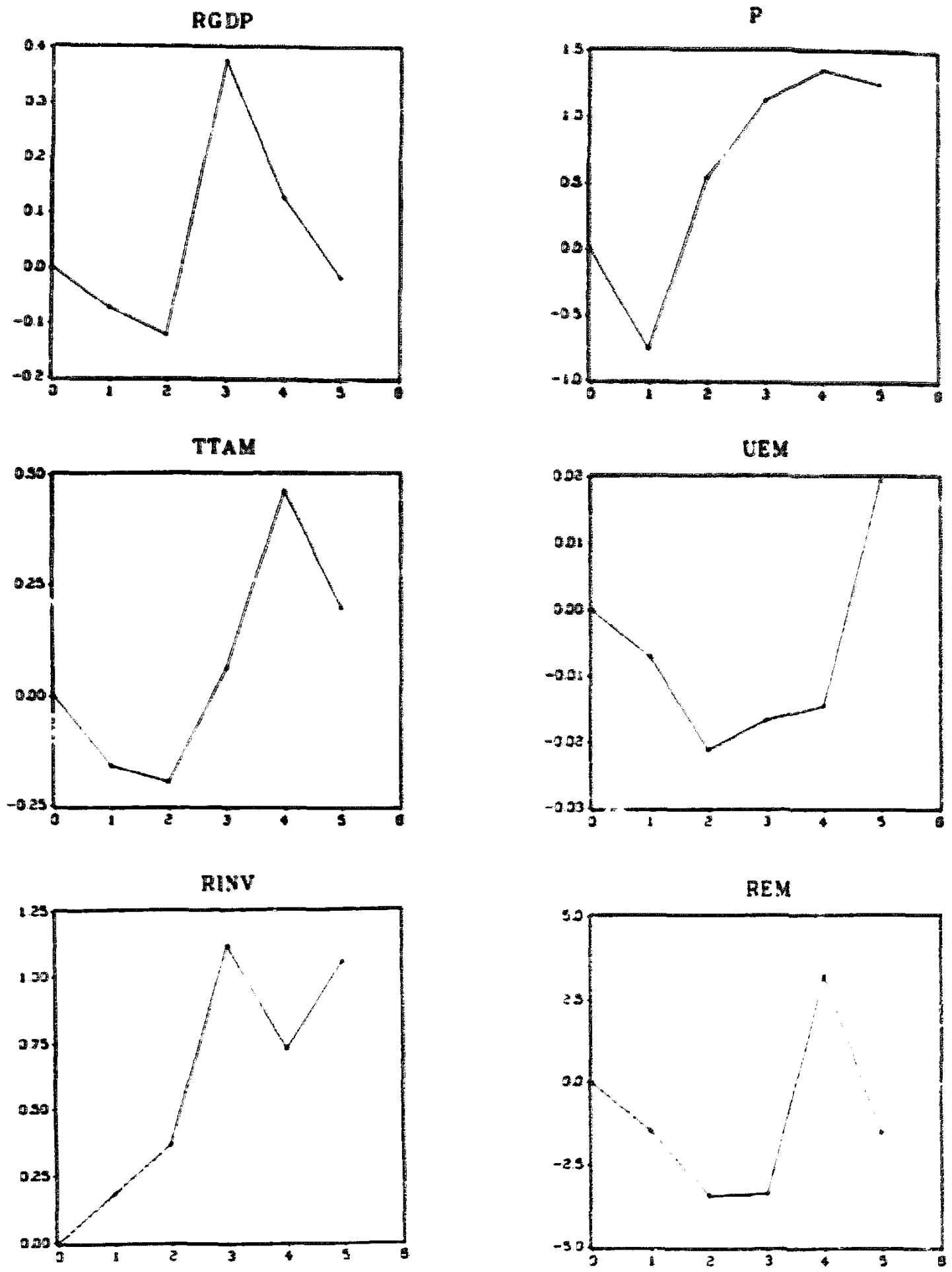

Fig. 1. Impulse responses to a shock in $M$.

( $M$ ) does not significantly influence the unemployment rate (UEM). However, as the economy reaches the peak after two periods and starts to slow down, the UEM and remittances (REM) start to rise steeply. One can provide the following economic explanation for the above result. Due to a given shock in the money supply, initially the aggregate demand of the economy is stimulated, thereby causing RGDP and RINV to increase. 
However, in the long run ${ }^{7}$ when the nominal money stock is held constant (because of a one period shock) and concurrently prices continuously rising (with lag), the real money balances will start to decline. This is expected to cause a slowdown in the economy resulting in a decline in real investment, GNP and employment and probably emigration of workers. The emigration of workers may cause an increase in the remittances in the long run.

The results produced by the impulse response function (IRF) of TTAM are also very interesting and seem to be consistent with the stylized facts of developing countries. The initial impact of the monetary policy $(M)$ on $T T A M^{8}$ appears to be negative and it is only after a year or so that TTAM gradually starts to rise. This result seems to support one of the widely accepted views regarding the thinness of financial markets in the rural or agricultural sector in Pakistan. The short-run impact of $M$ is much weaker on the agricultural prices vis-à-vis the manufacturing prices. However, with time, the effect of expansionary monetary policy does seen to percolate through the system and evantualiy the increase in agricultural prices dominates the manufacturing prices.

(b) A one standard deviation shock given to the fiscal variable also produces some interesting results as shown in fig. 2 . Unlike monetary policy, the shortrun effect of fiscal policy results in a weak response of $R G D P$ and a strong crowding effect on $R I N V$. Concurrently, the general prices $(P)$ tend to decline due to a net incrcase in the RGDP while the $T T A M$ initially improves sharply probabiy due to government expenditure policy programmes. In the long run, however, the support provided by the increased government expenditure $(R G E X)$, in terms of the development of infrastructure, induces real private investments ( $R I N V$ ) to increase. This increase in $R I N V$ consequently enhance $R G D P$ and leads to a reduction in the price ievel $(P)$ as well as TTAM. The initial crowding out of RINV seems to generate $U E M$ in the short run as well as in the long run. It is interesting to note that such a result is also produced by the monetary policy.

(c) The impulse response functions of external resources (REXR) and remittances $(R E M)$ produce similar results, at least for $R G D P$ and $R I N V$ as shown in figs. 3 and 4. In both cases, the short-run impact on RGDP and $R I N V$ seems to be very subdued. In fact, the results in figs. 3 and 4 seem to support the hypothesis that the role of remittances and external resources has been to stimulate private consumption (thereby causing some increase in

\footnotetext{
'Eichenbaum (1985) and others have cautioned about the reliability of the effects of impulse response functions (IRF) in the long run. The problem arises because in the long run the siandard error of IRF tends to be large. Our IRF results may be subject to this caveat and we caution the reader to view the long run results in such a perspective. We, however, wish to point out that a number of other studies, i.e. Burbidge and Harrison (198<, 1985), McMillin (1988), Sims (1980) and others have also analyzed the long run effects of IRF.

${ }^{8}$ Note that TTAM is defined as the ratio of prices in the agricultura scitor (AP) to that of the manufacturing (MP) sector.
} 

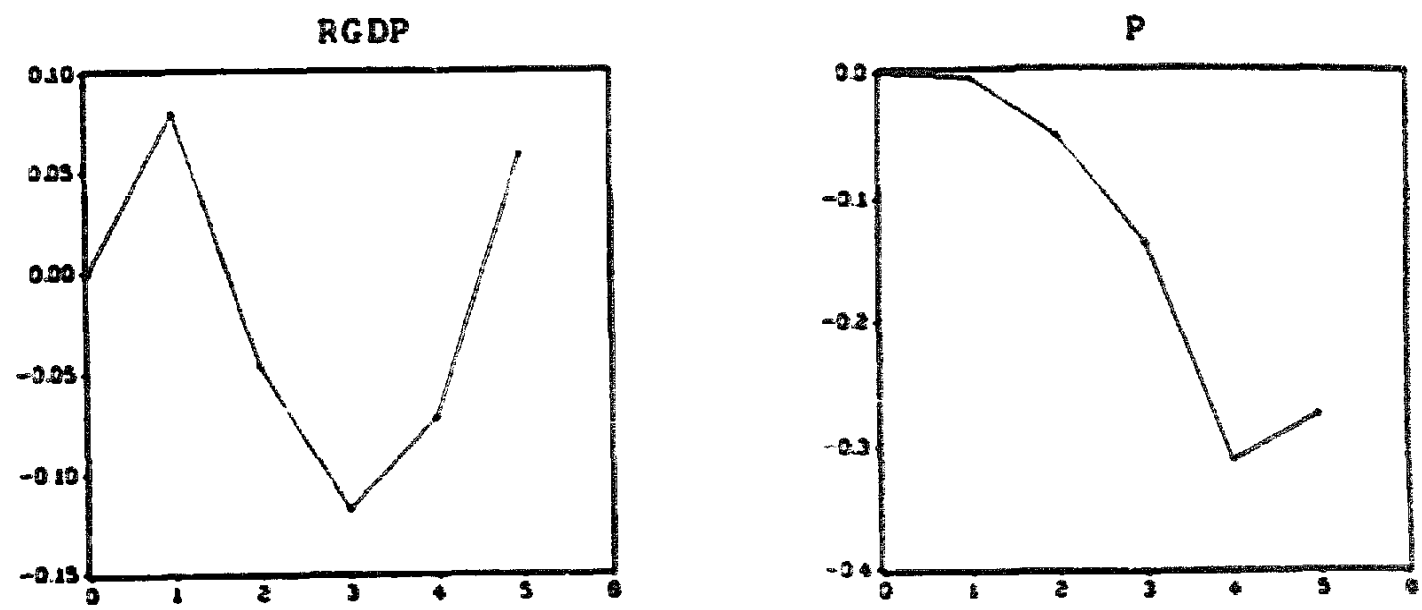

TTAM
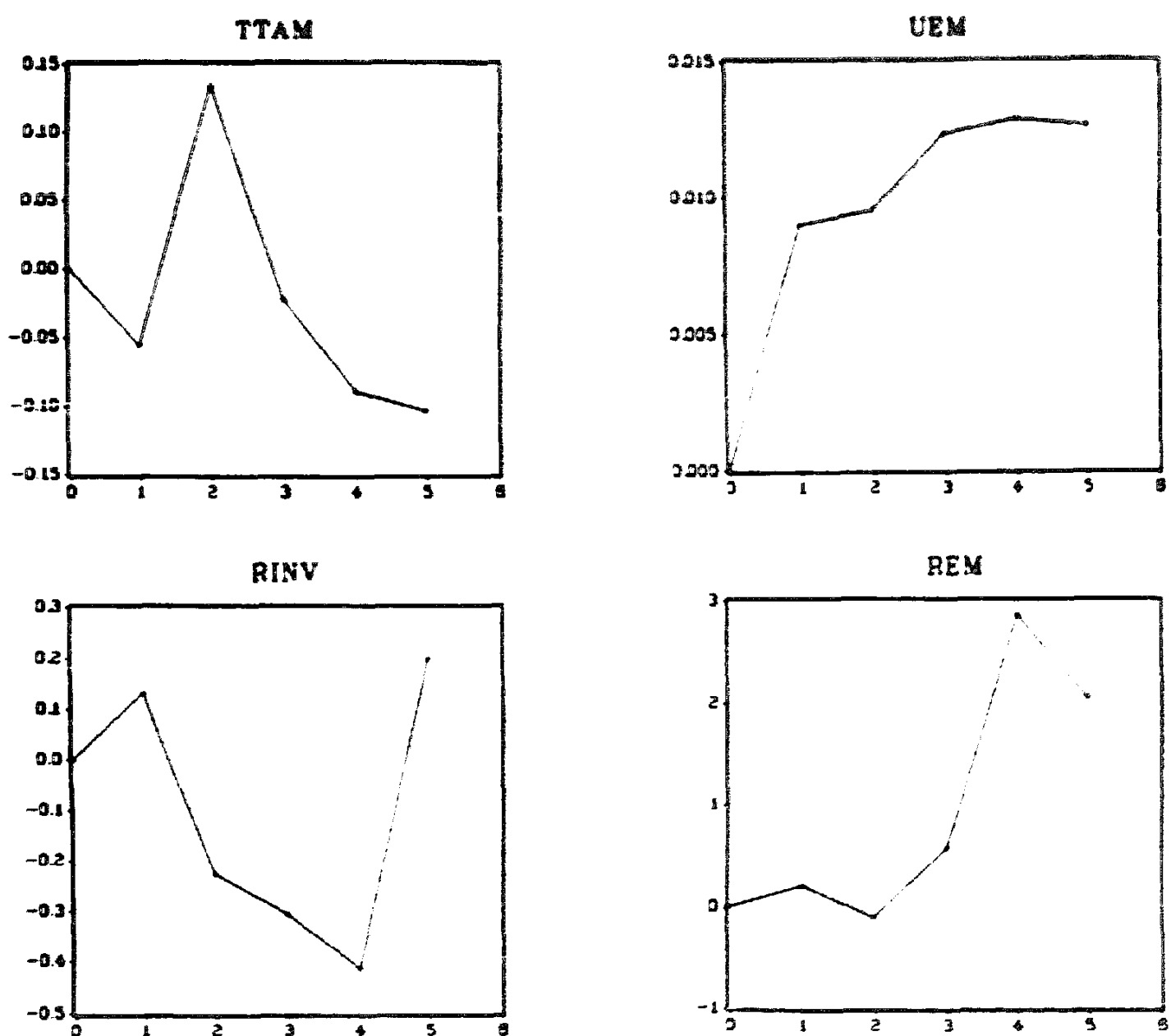

Fig. 2. Impulse responses to a shock in $R G E X$.

RGDP) without significantly enhancing the private investment of the economy either in the short run or in the long run.

Figs. $j$ and 4 also reveal that the short-run impact of external resources (REXR) on $P, T T A M$ and employment (opposite of $U E M$ ) is much stronger than the impact of remittances $(R E M)$ on these same variables. The reasons for having such different results can be explained as follows. A good part of 

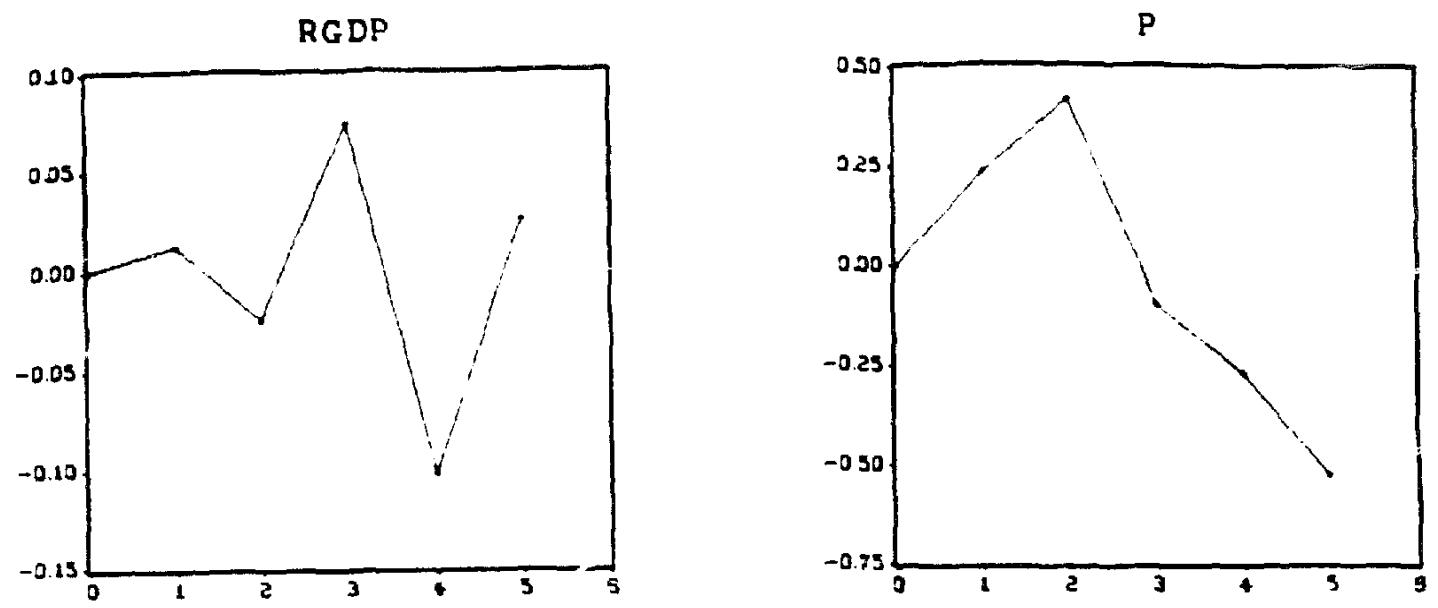

TTAM
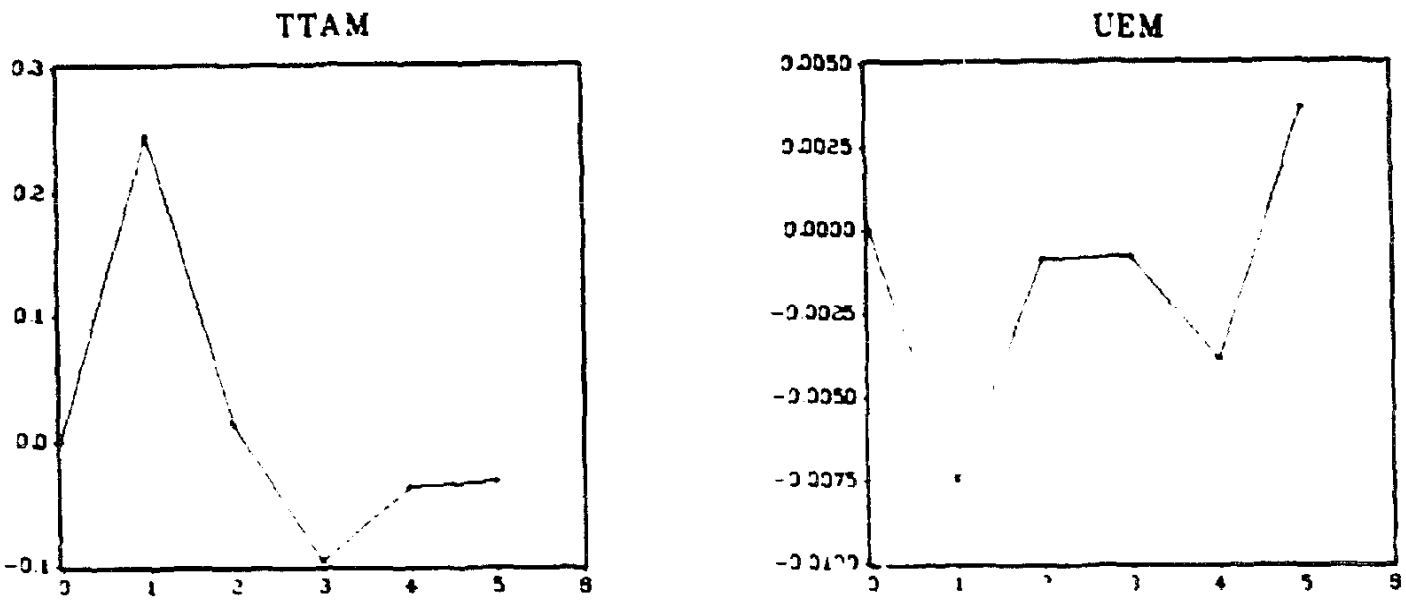

REM
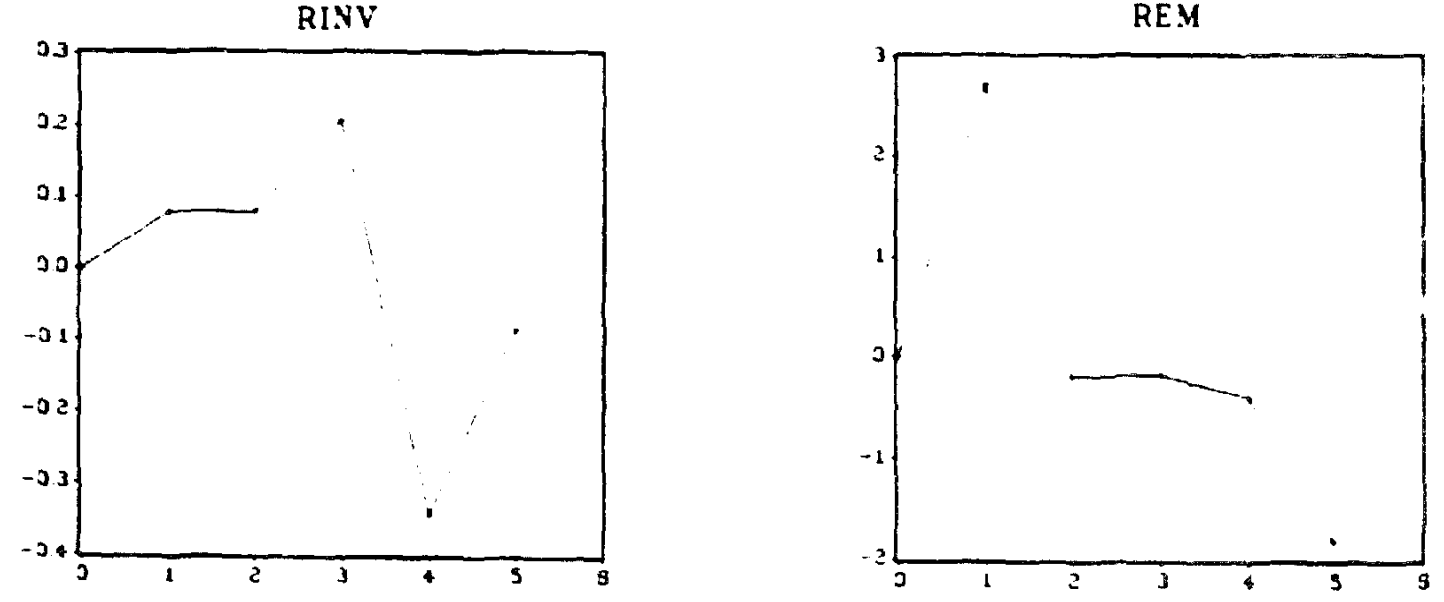

Fig. 3. Impulse responses to a shock in REXR.

the money from remitiances, at least in the initial stages, is likely to be saved rather than invested in physical capital. On the other hand, the funds from external resources $(R E X R)$ in the form of foreign aid and grants are made available and absorbed into the economic system much quicker and faster than the remittances $(R E M)$ sent by the expotriates. Consequently, $R E X R$ will cause a bigger increase in the general prices $(P), T T A M$ (because of aid 

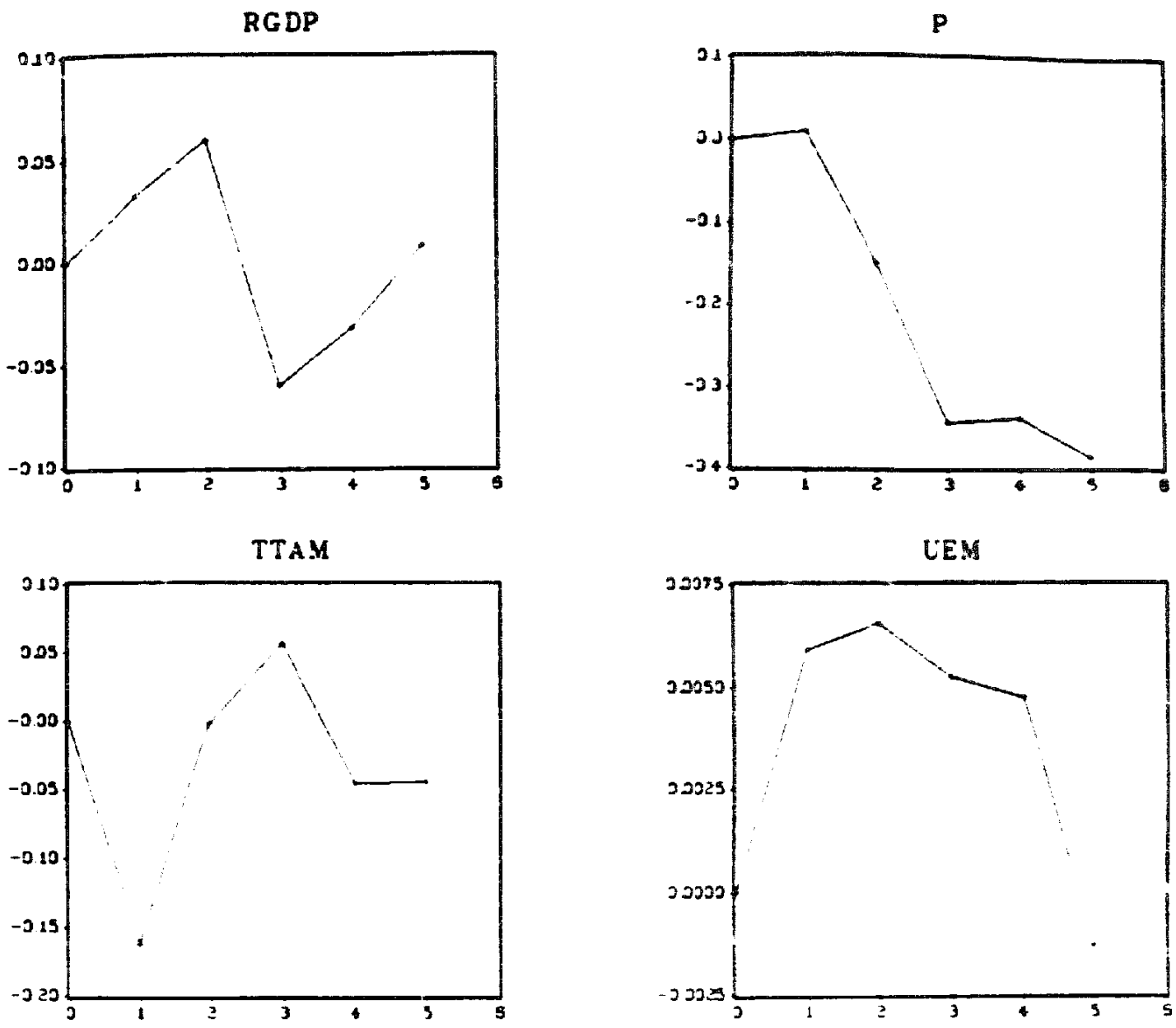

iniv

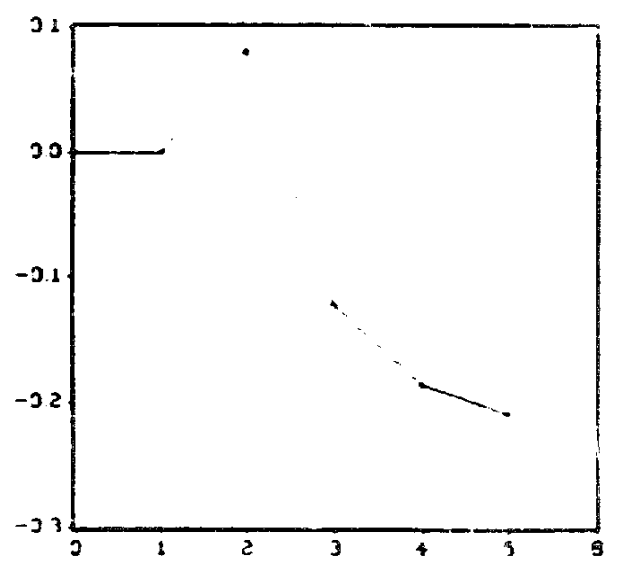

REM

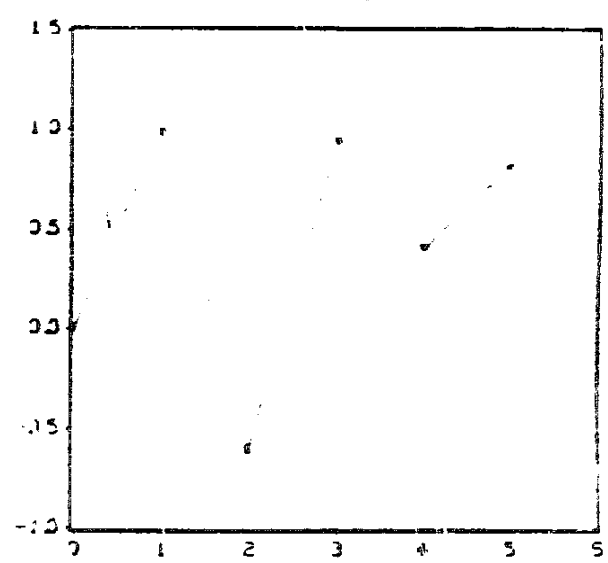

Fig. 4. Impulse responses to a shock in REM.

money directly going into the agricultural sector) and, in general, ceates more jobs.

The summary results of impulse responses discussed so far seem to suggest that fiscal policies have moderate short-rum effects on the RGDP. Hovever, in the long run, monetary policy seems to be more potent than fiscai policy 
in affecting $R G D P$ and prices in the economy. On the other hand, the external resources and remittances are largely used for consumption and do not significantly influence private investment.

As mentioned earlier, since VDCs can provide further insight into the macroeconomic effects of monetary and fiscal policies, the following discussion examines the summary results of VDCs.

Variance decompositions (VDCs). The results of the VDCs for all the variables are reported in table 2. Both direct and indirect effects are captured by the VDCs. Given that the main focus of the study is to analyze the impact of monetary and fiscal policies on RGDP we are, therefore, particularly interested in that portion of $R D G P$, which is explained by innovations to $M$ and RGEX. As expected, the direct effects of $M$ and $R G E X$ on itself are very high (almost $100 \%$ ) and this confirms the exogenous nature of these policy variables. On the other hand, a further analysis of table 2 indicates that a very small portion of the variance in $R G D P$ within a year is explained by innovations to $M(4.5 \%)$. In fact, innovations to $R G E X(36.8 \%), R E X P$ $(17.9 \%), R E M(16.7 \%)$ and RINV $(23.4 \%)$ explain most of the variation in $R G D P$ in that time period. However, within three years, innovations to $M$ explain $29.2 \%$ of the variance in $R G D P$ whereas innovations to $R G E X$ explain only $23.5 \%$ of the variance in $R G D P$. Innovations to $M$ explain $33.6 \%$ of the variance in $P$ after three years while the impact on $T$ TAM has a delayed effect and it goes only up to $27.3 \%$ even after five years. It is interesting to note that not only do innovations to RGEX explain a small portion of the variance in $R G D P$, but such innovations also have a small impact on the other target variable $(P)$. These results seem to be consistent with those of impulse responses.

Robustness of $V A R$ results. In order to test the robustness of the estimated VAR results, as suggested by Todd (1990), we compare the results of this paper with that of an earlier comparable study done by Chishti, Hasan and Mahmud (1989) [C-H*M (1989) hereafter]. The present model differs from that of the C-H-M (1989) study, in at least two important ways: (a) we added two more years of data and (b) an additional variable, TTAM, is also included in the present model. We believe this modification is a significant one and if the present model is nonrobust then, as pointed out by Todd (p. 20, 1990), the results of this study should differ dramatically from that of the C-H-M (1989) model.

Although a comparison of the results of the two specifications of the VAR models did not provide identical results, it is nevertheless, interesting to observe that the direction and the overall profile of the present study is very similar to that of the C-H-M (1989) model. In particular, the impulse response functions (IRF) presented in this paper closely resemble the $\mathrm{C}-\mathrm{H}-\mathrm{M}$ (1989) model at least for the comparable variables. In short, by carefully 


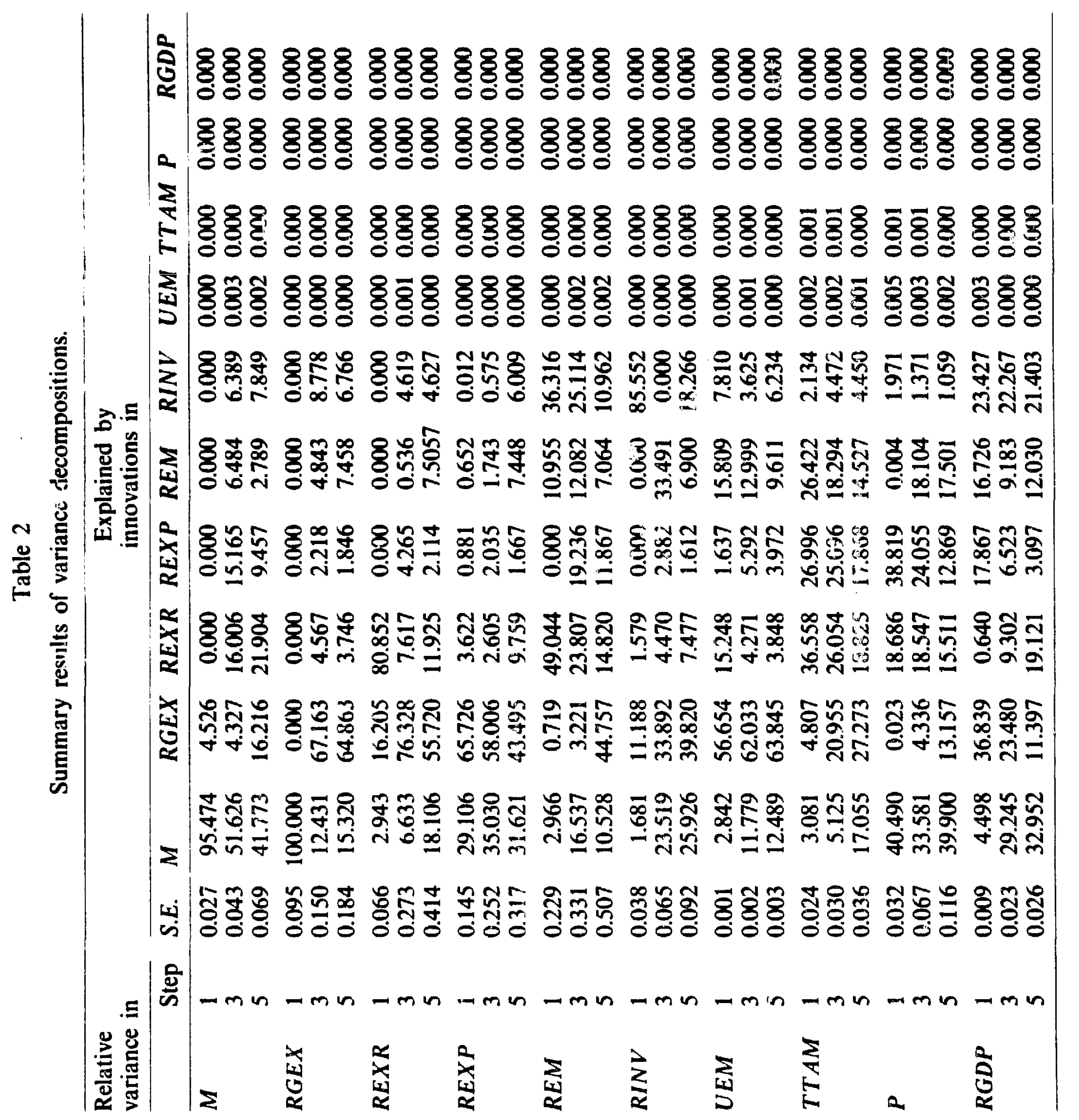


comparing the results of the two versions, we found no strong evidence to support the claim that our specification of the model is nonrobust.

\section{Conclusions}

Despite some sharp criticisms by Cooley and LeRoy (1985) and Eichenbaum (1985) on the usefulness of VAR to the macroeconometric model building, they all, nevertheless, agree that there are important uses of the VAR models. For instance, McMillin (p. 320, 1988) pointed oul that these models are pariculariy usefil ir the case of forecasting, analyzing the cyclical behaviour of the cconomy, the generation of stylized facts about the behaviour of the elements of the system which can be compared with existing theories or can be used in formulating new theories, and testing of theories that gcnera:c Granger-causality implications:. As suggested by Litterman (1979), the VAR procedure not only provides greater forecast accuracy (particularly, in the short run) than earlier standard structural models, but it can also be suitable in analyzing the impacts of policy shocks on the target variables. This study, therefore, examined the annual response of Pakistan's key nacroeconomic variables to anticipated and unanticipated shocks in policy variables using the innovative VAR technique proposed by Litterman (1979) and Sims (1986). A ten-variable annual macroeconometric model for the economy of Pakistan was estimated within the context of a VAR procedure over the period 1960 to 1988.

We believe this paper has demonstrated that VARs are a more nexible approach to macro modelling, particularly when the 'true' structura! model is unknown and that our study is the first attempt to apply such an approach in the case of Pakistan. The empirical resuits of this study are not only intuitive and consistent with the predictions of the standard nen reoclassica" (SNN) model, ${ }^{9}$ but based on these results, perhaps, one may also shed light on some of the important recurring macroeconomic issues and they are summarized below.

(a) The relative importance of fiscal and monetary policies in influencing the real sector is still a debatable issue. Taylor (1979), McCallum and Whitaker (1979) and others have theoretically argued in favour of fiscal policies whereas the proponents of SNN theory favoured monetary policy. Our empirical results based on the VAR approach indicate that the impact of fiscal policy shocks on real GDP seems to be very weak at least in the short

\footnotetext{
${ }^{9}$ For instance, one of the predictions of the SNN model with rational expectations is that both anticipated and unanicipated monetary effects have a mersistent positive impact on the real output variable and that the fiscal effects are much weaker [e.g. see Taylor (1986), Dungan and Wilson (1988) and Meredith (1989)]. Another prediction is that inflation is a monetary phenomenon.
} 
run. On the other hand, monetary policy shocks seem to drive up the real GDP in the economy in the long run. The fissal impact (via increase in governmest expenditure), in case of Pakistan, is weak because about $75 \%$ of the total current expenditure of the federal government is, in general. accounted for by defence and debt servicing [e.g., Pakistan Economic Surtey (1989-90)] which have no significant impact on GDP. The remaining expenditure is also expended on social and administrative services which again have typically low multipliers. The monetary impact (via increased money) is strong because private investment largely depends on credit. The debt-equity ratio for Pakistan has remained at roughly four since the seventies [e.g., Pakistan Economic Survy (1989-90)].

(b) Our empirical results using the VAR approdch seen to be intuitive tocause unlike the PIDE 1983 model (which argues that deficit inancing does not contribute to the monetary expansion and that monetary expansion does not explain changes in the general price level), the unanticipated monetary shocks after a short lag persistently raise the price level. Furthermore, the shocks from external resources $(R E X R)$ rather than the remittance add to the domestic inflation at least in the short run. The reason for this is that $R E X R$ is directly absorbed into the system whereas the REM is either saved or gradually spent in the real estate sector.

(c) II is also interesting to note that $R E X R$ and $R E M$ do not significantiy stimulate real private investments. Intuitively, one can argue that the reason for such a subduei impact is that, in Pakistan, a large portion of the inflow of $R E X R$ in terms of economic aids and grants goes to the public sectur (including defence) rather than generating capital in the private sector.

\section{References}

Burbidge. 1. and A. Harrison, 1984. Testing for the effects of oil-price rises using vector autoregressions, International Economic Review 25, 459-475.

Burbidge. J. and A. Harrison, 1985a, An historical decomposition of the great depression to determine the rote of money. Journal of Monetary Economics 16.45-54.

Burbidge. J. and A. Harrison, 1985 , (Innovation) Accounting for the impact of Iuctuations in U.S. variables on the Canadian, Canadian Journal of Economtes $18,784-798$.

Chishti. S.U., M.A. Hasan and S.F. Mahmud, 1989, Macroeconometric policies and Pakistan's economy, Pakistan Dewelopment Review, Papers and Proceedings, Part II 28. 717-728.

Cooley, T. and S. LeRoy, 1985, Atheoretical macroeconometncs: A critique, Jounal of Monetary Economics 16. 183-308.

Doan, T. 1989, RATS version 3.02 User's manul IVAR Econonetrics, Hinois).

Doan, T., R. Litterman and C. Sims, 1984 , Forecasting and conditional projection using realistic prior distribution, Econometric Review 3, 1-100.

Dungan, $P$. and T. Wilson, 1988 . Modellng anticipated and temporary fiscal policy shor sin a macro-econometric model of Canada, Canadian Joumal of Economics 21, 41-60.

Eichenbaum, M., 1985, Vector autoregression for causal inference? A comment, CamegisRochester Conierence Series on Public Pohlicy 22, 305-318.

Fuller, W.A., 1976, Introduction to statistical time-series (Wiley, New York).

Hasan, M.A. 1987, A rational expectations macro-econometric model of Pakistan's monetary policy since 1970s, Pakistan Development Review 26, 513-523. 
Hasan, M.A., 1990, Phillips curve analysis: Some experiences from Pakistan's economy, Journal of Economic Studies 17, 57-65.

King, S., 1983, Real interest raies and the interaction of money, output, and prices, Mimeo (Northwestern University, Evanston, IL).

Litterman, R., 1979, Techniques of forecasting using vector autoregressions, Working paper nn. 115 (Federal Reserve Bank of Minneapolis, Minneapolis, MN).

Litterman, R., 1984, Forecasting and policy analysis with bayesian vector autoregression mode!s. Federal Researve Bank of Minneapolis Quarterly Review (fall), 30-41.

Masosd, K. and E. Ahmed, 1980, The relative importance of autonomous expenditures and money supply in explaining the variations in induced expenditures in the context of Pakistan, Pakistan Economic and Social Review 18, 84-99.

McCallum, B. and J. Whitaker, 1979, The effectiveness of fiscal feedback rules and automatic stabilizers under rational expectations, Journal of Monetary Economics 5, 171-186.

McMillin, W., 1988, Money grr'wth volatility and the macroeconomy, Journal of Money, Credit and Banking 20, 319-335.

Meredith, G., 1989, Expectations, policy shocks, and output behaviour in a multi-country macroeconomic model, Mimeo (Department of Finance, Ottawa, Ont.).

Naqvi, S.N. and A. Ahmed, 1986, The preliminary revised PIDE 1982 macro-econometric model for Pakistan's economy (PIDE, Islamabad).

Naqvi, S.N., A.H. Khan, N. Khilji and A. Ahmed, 1983, The PIDE macro-econumetric model for Pakistan's economy (PIDE, Islamabad).

Runkle, D., 1987, Vector autoregression and reality, Journal of Business and Economic Statistics $5,437-442$.

Saqib, N. and A. Yasmin, 1987, Some relative evidence on the relative importance of monetary and fiscal policy in Pakistan, Pakistan Development Review 26, 541-549.

Sims, C., 1980, Macroeconomics and reality, Econometrica 48, 1-48.

Sims, C., 1982, Policy analysis with econometric models, Brookings Papers on Economic Activity $1,107-152$.

Sims, C., 1986, Are forecasting models usable for policy analysis? Federal Reserve Bank of Minneapolis Quartcriy Review, Winter, 2-16.

Sims, C., 1987, Comment, Journal of Business and Economics Statistics 5, 443-449.

Sims, C., 1989, Models and their uses, American Journal of Agricultural Economics 71, 489-494.

Spencer, D., 1989, Does money matter? the robustness of evidence from vector autoregression, Journal of Monetary Economics 5, 171-186.

Taylor, J., 1979, Estimation and control of a macroeconomic model wi'h rational expectations, Econometrica 47, 1267-1286.

Taylor, J., 1986, The treatment of expectations in a large multi-country econometric model', Paper prepared for Brookings Conference on Empirical Macroeconomic for Interdependent Economies, Washington, DC.

Todd, R., 1990, Vector autoregression evidence on monetarism: Another look at the robustness debate, Federal Reserve Bank of Minneapolis Quarterly Review, Spring, 19-37. 